\title{
Os empreiteiros de obras públicas e as políticas da ditadura para os trabalhadores da construção civil"
}

\author{
The public work contractors and the dictatorship \\ policies for construction workers
}

\author{
Pedro Henrique Pedreira Campos**
}

\begin{abstract}
Resumo- O presente artigo pretende analisar as políticas estatais da ditadura civil-militar brasileira (1964-1988) para os trabalhadores da construção civil, tendo em vista os interesses e o favorecimento dos empresários do setor, em particular os empreiteiros de obras públicas. Partindo de um aparato teórico-conceitual advindo do materialismo histórico, abordamos em linhas gerais as condições de trabalho proporcionadas nos canteiros de obras para os operários do setor, suas formas de organização e as limitações impostas à sindicalização e mobilização durante o período da ditadura. Abordamos também as condições de segurança e saúde do trabalhador, os acidentes ocorridos nas obras e as formas de atuação desses trabalhadores em greves, revoltas e quebra-quebras, em particular no período final do regime. Nossas conclusões indicam que as políticas para os trabalhadores em geral e da construção civil em particular ao longo do regime eram intensamente benéficas para os empresários do setor.

Palavras-chave: empreiteiros de obras públicas; empresários; ditadura civil-militar brasileira (1964-1988); Estado brasileiro; políticas públicas.
\end{abstract}

\begin{abstract}
This article aims to analyze the state policies of Brazilian civil-military dictatorship (1964-1988) for the construction workers, in view of the interests and favoring the businessmen of this sector, particularly public works contractors. From a theoretical and conceptual framework arising from historical materialism, we discuss in general terms the working conditions provided at sites for construction workers, their forms of organization and the limitations imposed on unionization and the mobilization during the dictatorship. We also approach the safety and health of the worker, accidents occurred in the sites and the ways of action of these workers in strikes, riots and smashing, particularly in the final period of the regime. Our conclusions indicate that policies for workers in general and construction in particular along the Brazilian dictatorship were intensely beneficial for the contractors.
\end{abstract}

Keywords: contractors; businessmen; Brazilian civil-military dictatorship (1964-1988); Brazilian State; public policies.

\footnotetext{
* O presente artigo constitui trecho adaptado de capítulo de nossa tese de doutorado, defendida em 2012 no Programa de Pós-Graduação da UFF. A pesquisa que deu origem a este ensaio contou com o apoio do CNPq e da Faperj. ** Professor Doutor do Departamento de História e Relações Internacionais pela UFRRJ. Correspondência: Rua Real Grandeza, 193 / 802. Botafogo. Rio de Janeiro - RJ. CEP: 22281-035. E-mail: <phpcampos@yahoo.com.br>
} 


\section{Introdução}

No primeiro semestre 2014, convidado pela Comissão Nacional da Verdade, fui a um evento do Grupo de Trabalho da comissão dedicado ao tema da repressão aos trabalhadores e sindicatos ao longo da ditadura, realizado na Assembleia Legislativa do Estado de São Paulo (Alesp). Após minha fala, na qual expus o tema da minha tese de doutorado ${ }^{1}$ - acerca da relação dos empresários brasileiros da construção civil e a ditadura civilmilitar -, um sindicalista que estava no evento me interpelou se eu não possuía dados sobre a situação dos trabalhadores e acidentes ocorridos no período. Após apresentar a ele, em reservado, as informações e estatísticas que eu abordei de maneira lateral em minha pesquisa e que apontavam para milhares de mortos em acidentes de trabalho no país ao ano, ele fez uma intervenção pública no seminário: "Eram cinco mil mortos em acidentes de trabalho por ano. Isso é um genocídio." Em uma fala muito certeira e equilibrada, o sindicalista sinalizava que esses eram apenas os índices oficiais e que, mesmo assim, há de se ponderar que nem todos os casos de óbitos no local de trabalho teriam sido estritamente frutos de acidentes, sendo possível que a causa da morte tenha sido outra. Além disso, ressaltava que as cifras elevadas indicavam o desleixo que a ditadura legava para a vida e a segurança dos operários em seu local de trabalho (BRASIL, 2014).

O presente artigo pretende contribuir, de maneira modesta, para a questão do tratamento dado aos trabalhadores durante a ditadura, com ênfase nas políticas para os operários da construção civil, tentando aferir em que medida estas incorriam em um beneficiamento aos empresários do setor. Muitas vezes, quando o tema dos crimes cometidos pela ditadura é levantado, são ressaltados os casos de militantes da esquerda armada que foram barbaramente perseguidos, presos, torturados e assassinados. Apesar da relevância e não-elucidação plena ainda de vários desses casos, entendemos que é urgente também conhecer mais profundamente os crimes perpetrados contra os trabalhadores em seu ofício, contra sindicalistas, operários e agentes diversos das classes subalternas, não necessariamente vinculados a movimentos de oposição à ditadura. Acreditamos que há aí um vasto mundo a ser estudado e desvendado.

Marx ressalta n'O Capital (1867) várias formas usadas pelos empresários para ampliar suas margens de lucro. No que concerne aos trabalhadores, ele verifica estratégias dos capitalistas para prolongar a jornada de trabalho, dentro e fora da legalidade, o que resulta na mais-valia absoluta. Com consequências diretas também sobre os operários, Marx nota que os donos de fábrica faziam economia no capital constante com o objetivo de

\footnotetext{
${ }^{1}$ Defendida na UFF em 2012 com o título de "A Ditadura dos Empreiteiros: as empresas nacionais de construção pesada, suas formas associativas e o Estado ditatorial brasileiro, 1964-1985".
} 


\section{AeVistg all paUtg}

\} OS EMPREITEIROS DE OBRAS PÚBLICAS - CAMPOS, P. H.P. \}

obter maiores ganhos, superlotando recintos estreitos e insalubres, economizando em edificações, acumulando maquinaria perigosa à saúde do trabalhador e omitindo-se na proteção do mesmo².

No que diz respeito à indústria da construção no Brasil, notamos o uso de mecanismos análogos pelos empresários com o fito de elevar o lucro em cada empreendimento. No caso específico da ditadura, essas práticas foram escoradas em políticas públicas que facilitavam a ampliação da exploração do operário e a maximização do lucro dos empresários, o que ficou evidente na política salarial e na parca fiscalização sobre as condições de higiene e segurança nos canteiros de obras. Portanto, outra face do beneficiamento dos empreiteiros durante o regime civil-militar se fez evidente nas políticas estatais para a classe trabalhadora.

\section{Condições de trabalho e organização dos operários na construção pesada}

O Golpe de 1964 representou uma dura derrota para os trabalhadores brasileiros em geral. O novo equilíbrio de classe imposto pelo regime foi intensamente negativo para as classes subalternas, com medidas de contenção dos salários, fim da estabilidade nas empresas privadas, instituição de poupanças compulsórias, fim do direito de greve e política de repressão sindical. Paul Singer (1977) destaca a inflação como uma forma de poupança forçada que transferia renda do trabalho para o capital e, com a liberação dos preços antes tabelados, o custo de vida se elevou em $80 \%$ apenas em 1964. Dando suporte à política salarial, o governo destituiu 563 diretorias de sindicatos e interveio em 4 das 6 confederações de trabaIhadores. Em seu lugar, foram impostos interventores e os sindicatos passaram a ter um viés mais assistencialista e menos político, sendo os antigos líderes operários presos, cassados em seus direitos políticos ou assassinados. Tornou-se prática a elaboração de "listas negras", nas quais constavam os nomes dos operários mais combativos, que tinham entrada negada nas empresas $^{3}$. Com os seus mecanismos de pressão cerceados, os trabalhadores viram o poder de compra dos seus salários se reduzir ano a ano até 1974 e lançaram mão de horas extras e do trabalho feminino e infantil, de modo a completar a renda familiar (GORENDER, 1987). A piora das condições de trabalho e vida foi mais grave para os trabalhadores não qualificados, o que levou Marini (2000) a se referir a uma superexploração da força de trabalho e lanni (1981), a uma mais-valia extraordinária.

\footnotetext{
${ }^{2}$ Ainda na obra marxista, sobre o tema das condições de vida e labuta dos trabalhadores no século XIX, há também a obra de ENGELS, Friedrich. A situação da classe trabalhadora na Inglaterra. 2ª ed. São Paulo: Global, 1988 [1845]. ${ }^{3}$ Sobre o beneficiamento de empresários, inclusive com a repressão aos trabalhadores, vale travar contato com a recente pesquisa desenvolvida por Horacio Verbitsky e Juan Pablo Bohoslavsky sobre o caso da ditadura argentina, Cuentas Pendientes: los cómplices económicos de la dictadura. Buenos Aires: Siglo XXI, 2013.
} 
Esse novo quadro se impôs na indústria de construção de maneira cabal, dado ser esse um dos setores que mais empregava força de trabalho. O salário mínimo, que servia de marco para outros salários, era usado na construção como referência prioritária, sendo que a média básica de proventos variava ali de um a dois salários mínimos, apesar de ser muito comum no setor também o regime de salário-hora (OLIVEIRA, 2003; FUNDAÇÃO JOÃO PINHEIRO, 1984). Pesquisa do Dieese indica que os salários reais na indústria de construção tiveram queda em toda década de 1970 (apud O EMPREITEIRO, 1978).

O Golpe de 1964 redundou em ações contra sindicatos também na construção. Assim, o ativo sindicato dos trabalhadores da indústria da construção de Brasília, no qual tinha força o PCB, sofreu intervenção do governo, que afastou trabalhadores de sua direção. Houve cassações no Rio e para o Sindicato dos Trabalhadores da Indústria da Construção da cidade foi nomeado um interventor (SOUSA, 1994). Os operários empregados nas empreiteiras tinham a sua própria agremiação, o Sindicato dos Trabalhadores da Indústria da Construção Pesada (Sintrapav), que não contava com a confiança dos operários e não teve grande combatividade durante o regime. $\mathrm{O}$ sindicato tinha como padroeiro São Judas Tadeu, cujo dia era comemorado com festa em 22 de outubro, geralmente com a presença de um representante do sindicato patronal, o Sinicon ${ }^{4}$ (SINICON, 1984). Em 1981, o sindicato dos trabalhadores conseguiu na justiça do trabalho multar 35 empresas por desrespeitar esse feriado (KLAUSMEYER, 1988).

A rotatividade dos trabalhadores em postos de trabalho, elevada após a instituição do FGTS, era especialmente significativa na construção. Pesquisa encomendada ${ }^{5}$ pelo sindicato dos trabalhadores da indústria da construção civil junto ao Dieese, em 1978, apontava que 34\% dos operários do setor ficava até um ano na empresa e outros $37 \%$ entre 1 e 2 anos, sendo que a rotatividade era mais significativa entre os trabalhadores nãoqualificados, e só $5 \%$ desses ficavam mais de 4 anos na mesma empresa. Isso ocorria por características próprias do setor, como o fato de empregar parcela de mão-de-obra apenas para uma obra, desempregando-a em seguida. De maneira discriminatória, o engenheiro Aloysio Pinto, entrevistado pela revista O Empreiteiro (1978), explicava a tendência pelo "primitivismo dos trabalhadores da construção", sendo essa marca da "própria índole do brasileiro [, que] é de não parar muito tempo num só lugar". Alegando "espírito aventureiro", o engenheiro sugeria que "entretanto a variação dos salários de uma empresa para outra influi muito no aumento da rotatividade."

A indústria de construção constituía a principal porta de entrada para os trabalhadores na cidade e empregava larga margem de mão-de-

${ }^{4}$ O Sinicon é o Sindicato Nacional da Construção Pesada, criado em 1959, e um dos objetos centrais de nossa pesquisa de doutorado. No período, a sigla abreviava o longo nome de Sindicato Nacional da Indústria da Construção de Estradas, Pontes, Portos, Aeroportos, Barragens e Pavimentação.

${ }^{5}$ Os dados da pesquisa foram publicados na Revista O Empreiteiro. Edição de outubro de 1978, n 129. 


\section{AeVistg all paUtg}

\} OS EMPREITEIROS DE OBRAS PÚBLICAS - CAMPOS, P. H.P. \}

obra não qualificada. Uma característica particular do operário do setor era a sua origem sobretudo rural, sendo muitos deles oriundos do Nordeste. Pesquisa da Fundação Getúlio Vargas (FGV) ${ }^{6}$ sobre a força de trabalho na indústria da construção na Guanabara, em 1972, apontou que 55\% dos trabalhadores vinham do meio rural e apenas $25,3 \%$ do estado do Rio. Ronaldo Coutinho (1980) fez estudo de campo com esses trabalhadores e destaca que eles não saíam da zona rural para a cidade em busca de ascensão social, mas por questões de sobrevivência, dado o baixo nível salarial, dificuldades e endividamento permanente na região de origem. O trabalhador que vinha do campo muitas vezes não tinha onde morar na cidade e era comum que ele dormisse no canteiro. Um médico de construtora carioca notou que o canteiro era um pequeno pedaço do Nordeste, e as próprias formas de diversão e lazer na cidade eram em regiões como a feira de São Cristóvão e os forrós do Largo do Machado e do Catete, esses próximos aos canteiros de obras do metrô (SOUSA, 1978). Pesquisa da Fundação Jorge Duprat Figueiredo de Segurança e Medicina do Trabalho (Fundacentro) aponta ainda que, em média, $40 \%$ dos trabalhadores da construção eram analfabetos ou semianalfabetos nos anos 1970 (apud ROCCA, 1991). Sobre o fato de ser tipicamente o primeiro emprego do trabalhador rural ao chegar à cidade, o presidente do Sindicato dos Trabalhadores da Indústria de Construção Civil de São Paulo, Décio Lopes, afirmou em 1979:

Na verdade, os verdadeiros profissionais estão se extinguindo. Normalmente os que trabalham 10 ou 12 horas numa obra logo mudam para uma fábrica, a fim de ganhar melhor salário, porque além do mais esse operário necessita de bom alojamento e alimentação adequada, o que raramente encontra. (apud O EMPREITEIRO, 1979, p. 56)

A realização de horas extras na indústria de construção era muito comum e os regimes diários de trabalho chegavam a 18 horas em obras de grande porte. As condições gerais do canteiro eram alvos de queixas dos trabalhadores e motivos de revoltas, principalmente no final da ditadura. As reclamações giravam em torno do atendimento médico, condições de alojamento, cantina, alimentação, higiene e truculência dos seguranças, que muitas vezes andavam armados pelos canteiros e usavam a força. $\mathrm{O}$ repórter Tim Lopes, em 1980, morou e trabalhou como operário alguns dias no canteiro de obras do metrô do Rio, onde vivenciou o cotidiano e colheu queixas dos trabalhadores, escrevendo depois matérias em jornais (O EMPREITEIRO, 1980). Segundo a revista $O_{\text {Empreiteiro }}^{7}$ (1975), um caso "escandaloso" foi o de empreiteira que prestava serviços para a Telesp e provia péssimas condições de trabalho para os operários, que estavam em

\footnotetext{
${ }^{6}$ Citada por Nair Heloísa Bicalho de Sousa em Operários e Política: estudo sobre os trabalhadores da construção civil em Brasília. Dissertação de mestrado em Ciências Sociais. Brasília: UnB, 1978. p. I-XIII.

${ }^{7}$ Revista O Empreiteiro. Edição de fevereiro de 1975, nº 85.
} 


\section{Revista pll pavtg}

\} OS EMPREITEIROS DE OBRAS PÚBLICAS - CAMPOS, P. H.P. \}

situação de "escravidão branca". No final da ditadura, a imprensa passou a dar espaço para essas questões, o que não ocorria nos anos mais fechados do regime (SOUSA, 1994).

A força de trabalho usada nas obras era recrutada de três formas: ou era do quadro próprio da empresa, com seus engenheiros e técnicos qualificados e experientes; ou contratada especificamente para o empreendimento; ou oriunda de uma empresa arregimentadora de mãodeobra, as subempreiteiras de trabalhadores, chamadas "gatas" (CHAVES, 1985). Esse último era o regime mais precário de trabalho, já que não pressupunha vinculação direta com a empresa realizadora da obra. Outro trabalhador usado era o de origem prisional. Tal qual outros regimes autoritários do século XX, no Brasil foram usados trabalhadores que viviam sob cárcere, inclusive com denúncias de uso de presos políticos em obras públicas na ditadura. Referindo-se à construção de rodovia na floresta amazônica, o diretor da empreiteira Camargo Corrêa, Wilson Quintella (2008, p. 219), afirma que foram enviados 50 presos de Cuiabá para ajudar nas obras e que a construtora teve problemas na região com seringueiros, que viam seus empregados fugirem de um sistema de escravidão por dívida para trabalharem para a empresa. O diretor da construtora paulista relata outro caso de trabalhadores vindo da prisão:

Recrutava-se todo o pessoal disponível, até mesmo os foragidos da prisão - um dia descobriram que um dos nossos melhores armadores de ferro havia escapado da cadeia de S. Bernardo do Campo. Contase ainda que o delegado de uma cidade próxima à obra, Porto Epitácio, um dia abriu a porta da cadeia e mandou todos os seus presos trabalharem na barragem, assim como ocorreu na delegacia de Cuiabá, quando iniciamos a BR-29.

Esse testemunho mostra como o uso mão-de-obra prisional parece ter sido comum em obras com demanda de muitos trabalhadores, principalmente em regiões remotas.

Um regime especial de trabalho se dava nas obras de barragens e hidrelétricas, onde eram criados alojamentos para milhares de trabalhadores, com um sistema de logística complexo e, muitas vezes, falho. Nesses ambientes, quando ocorriam protestos de operários, os resultados eram em geral mais violentos, dadas as condições de confinamento e distância do canteiro em relação a povoados e à região de origem do trabalhador. Na reportagem da revista O Empreiteiro (1970, no25) sobre a obra da UHE de Jaguara, tocada pela Mendes Júnior em Minas, foram apresentadas as condições gerais do canteiro. A construtora ficava responsável pelo alojamento e o cuidado com os trabalhadores, no que o órgão contratante (a Cemig) não interferia. Os dirigentes da empreiteira se gabavam de manter junto à obra uma vila residencial para 4.000 pessoas, escolas para 430 crianças, hospital com 25 leitos, centro cirúrgico, gabinete dentário, clube para ati- 


\section{ReVistg all PaVtg}

\} OS EMPREITEIROS DE OBRAS PÚBLICAS - CAMPOS, P. H. P. \}

vidades esportivas e sistema no qual o trabalhador não pagava aluguel, água ou energia. Murillo Mendes afirmou que o ambiente contava com "todos os requisitos mínimos de conforto [...] sem adotar uma política paternalista". E dizia pagar bem os operários: "Quanto ao nível salarial do pessoal que trabalha na obra, basta citar que em recente levantamento foi constatado que $99 \%$ das casas possuem televisores e outros eletrodomésticos". Uma forma de aquietar os trabalhadores e garantir ambiente tranquilo era prover sinal de TV: "Para que a imagem de televisão chegasse lá, a empresa mandou instalar, por sua própria conta uma torre retransmissora." Havia comércio de alimentos explorado por particulares, com supervisão da empreiteira, "para evitar especulação". Mendes dizia se preocupar com a segurança, mantendo 47 homens circulando na obra, e que todos acidentes eram registrados e analisados pela Comissão Interna de Prevenção de Acidentes (Cipa), sendo o índice, segundo ele, baixo (apud O EMPREITEIRO, 1970, p. 34).

Apesar da descrição do empresário, as reclamações de operários sobre as condições de vida e trabalho em canteiros de hidrelétricas eram muitas e as reações viriam de forma dura no final da ditadura. Mais que os salários e as condições de trabalho, o tema mais em voga no que toca às relações trabalhistas na construção eram os acidentes e a saúde do trabalhador.

\section{Acidentes de trabalho e culpabilização dos operários}

Resta saber que no Quarto Centenário o carioca, esse otário, vai ter água pra chuchu. Pois tem morrido um bocado de operário pra aliviar nosso calvário com a adutora do Guandu (MORAES, 1966, p. 119).

A citação de Vinícius de Moraes, datada de janeiro de 1965, pode indicar como uma característica histórica das condições de trabalho no Brasil foi potencializada pela ditadura, a do alto índice de acidentes de trabalho. Com o objetivo de produzir mercadorias baratas e elevar as taxas de lucro, os empresários economizavam em mecanismos de segurança para os trabalhadores, acarretando altos índices de acidentes, muitos letais, além de doenças relacionadas ao trabalho. Com os novos mecanismos institucionais, como a retenção da justiça trabalhista e a reformulação do sistema de previdência, os números de acidentados no trabalho se multiplicaram, acompanhando o crescimento econômico e o tacanho ou nulo controle sobre as empresas que não respeitavam a legislação e desconsideravam a saúde de seus funcionários.

A Organização Mundial de Saúde (OMS) fez relatórios sobre o assunto e denunciou as condições de trabalho no país, mostrando sua liderança estatística mundial no quesito. O organismo internacional indicava que, dos 77 milhões de trabalhadores brasileiros, 1,47 milhão haviam se 


\section{Revista pll paltg}

\} OS EMPREITEIROS DE OBRAS PÚBLICAS - CAMPOS, P. H.P.\}

acidentado em 1972, segundo os registros oficiais (O EMPREITEIRO, 1974). O próprio presidente da República ressaltou em cerimônia de posse do novo presidente da Câmara Brasileira da Indústria da Construção (CBIC), em 1980, que o país era recordista em números de acidentes de trabalho, registrando 1,5 milhão de casos anualmente, e que a indústria de construção tinha um papel central nessa estatística (apud O EMPREITEIRO, 1980). Vários desses acidentes eram mortais e, segundo a Folha de São Paulo, 2.559 morreram em acidentes de trabalho em 1971, 4.001 em 1975, chegando a 4.824 em 1980, índice similar aos da primeira metade dessa década (apud KLAUSMEYER, 1988). Já a Organização Internacional do Trabalho (OIT) trazia dados bem diferentes, contabilizando 8.892 óbitos por trabalho no Brasil só no ano de 1980, contra 4.400 nos EUA, que tinha o dobro da população economicamente ativa brasileira (apud ROCCA, 1991).

A parcela significativa representada pela construção nesses índices era ressaltada pela revista O Empreiteiro, em editorial em 1974: "Neste contexto, o setor de Construção está consciente que lidera as estatísticas de acidentes, disparando na frente de outros setores industriais." Nesse ano, foram 400 mil acidentes na construção segundo a revista e 1.796 .761 , segundo a Fundacentro (apud ROCCA, 1991) ${ }^{8}$. A importância do setor nos acidentes de trabalho não era nova e no Estado Novo, a construção era a terceira responsável por trabalhadores acidentados no Rio (LOBO, 1992).

Várias eram as doenças verificadas entre os operários da construção. Em função do trabalho pesado e da alimentação insuficiente provida pela empresa, a desnutrição era um mal comum entre os trabalhadores do setor. Com a exposição à luz do sol, havia câncer de pele e hiperpiresia. $\mathrm{O}$ trabalho com máquinas que emitiam altos ruídos, muitas vezes sem o equipamento adequado, levava a distúrbios no ouvido interno e perturbações psíquicas, insônia e outras doenças. O trabalho com materiais radioativos, como o pó de amianto, era outro perigo para o trabalhador e levava a patologias próprias, havendo também a "alergia de pedreiro", reação à poeira comum entre operários da construção. O trabalho com ar comprimido levava à intoxicação com nitrogênio e problemas ósseos, sendo esse distúrbio comum na construção pesada, nos serviços de fundações (KLAUSMEYER, 1988). Os tubulões usados em obras de pontes requeriam o trabalho com ar comprimido, levando à necrose do osso e desintegrando as juntas ósseas no ombro e quadris. Essa forma de lesão só começou a ser controlada no Brasil em 1971, sendo numerosa em obras como a ponte Rio-Niterói, onde foram registrados 45 mil casos de doença de descompressão e outros de necrose asséptica. No metrô de São Paulo, foram contabilizados 59.284 casos da enfermidade entre os trabalhadores (O EMPREITEIRO, anos 1974 e 1975) 9.

${ }^{8}$ De acordo com essa mesma fonte, entre 1971 e 1976, os acidentes anuais no setor variavam de 1,3 a 1,9 milhões de casos.

${ }^{9}$ Revista O Empreiteiro. Edições no 82, 86, 89, 90, 92, 93 e 94. 


\section{AeVistg all paUtg}

\} OS EMPREITEIROS DE OBRAS PÚBLICAS - CAMPOS, P. H. P. \}

Na construção pesada, a principal causa de acidentes eram as quedas, havendo também casos com quedas de ganchos, objetos e torres, choques elétricos, desmoronamento de barrancos e de valas, além de acidentes envolvendo maquinário, desabamentos, explosivos, estruturas provisórias e materiais radioativos (O EMPREITEIRO, 74). Alguns acidentes na construção pesada durante a ditadura vieram a público, como situações com vários mortos na construção da ponte Rio-Niterói, Itaipu e outros grandes empreendimentos. Um caso ocorreu no metrô do Rio em 1978, com "o colapso da lança de guindaste no centro, na Cinelândia; o incêndio nos alojamentos dos operários e o rompimento da laje no Centro de Manutenção, que matou dois operários e feriu muitos outros." (O EMPREITEIRO, 1978, p 16). Nesse mesmo trecho da obra, tocado pela Cetenco, havia denúncias de má qualidade das refeições dos operários e "maus tratos infligidos por guardas de segurança que policiam os canteiros de obras e tratam os operários como delinqüentes." (O EMPREITEIRO, 1978, p. 3). Na rodovia dos Imigrantes, realizada junto a encostas da serra do Mar, operários fugiram temendo "novos deslizamentos de terra no canteiro, que ocorreram por falta de contenção." (O EMPREITEIRO, 1975).

Eram comuns também os acidentes em empreendimentos imobiliários urbanos, apesar de não gerarem tantas vítimas por vez quanto na construção pesada. No final da ditadura, a imprensa passou a noticiar de maneira mais frequente os casos e, no início dos anos 1980, saíram matérias em jornais cariocas sobre morte de operário em obra em Niterói, outra no Guarujá, uma por rompimento do cinto de segurança no $33^{\circ}$ andar da torre do Rio Sul, no Rio (obra a cargo da Odebrecht), dentre outras. Quando a vítima era o operário, as repercussões do acidente eram limitadas, o que não ocorria quando o lesado estava além dos muros do canteiro, principalmente em certas regiões da cidade. Em 1981, uma pedra foi lançada de dentro de um canteiro no Leblon e matou um homem que passava pela rua. O caso teve grande divulgação na imprensa e um operário do empreendimento, de responsabilidade da Gomes de Almeida Fernandes (Gafisa), foi a público admitir sua "culpa", afirmando que tinha ingerido bebida alcoólica e, por isso, agira incorretamente, levando ao lançamento do objeto. Com a culpabilização do peão da obra, ele recebeu a punição e o caso foi encerrado (KLAUSMEYER, 1988).

Esse último exemplo é representativo de uma característica geral no setor, a culpabilização do operário pelos acidentes. Em cada incidente no canteiro, o empregador era obrigado a preencher uma Comunicação de Acidente de Trabalho (CAT) e nela punha os motivos para o ocorrido. Maria Klausmeyer (1988) notou que a maioria dos acidentes tinha como causa registrada "atos inseguros" realizados pelos funcionários. Em seu estudo quantitativo, as motivações principais assinaladas para os acidentes eram ações impróprias, inadequadas ou inseguras por parte dos operários, 


\section{hevigta all pgutt}

\} OS EMPREITEIROS DE OBRAS PÚBLICAS - CAMPOS, P. H.P. \}

além de imprudência, negligência, distração ou desatenção. A culpabilização recaía sobre o indivíduo e sua personalidade.

Essa marca era visível nas obras públicas e, segundo a revista $O$ Empreiteiro (1974, p. 3), os acidentes no setor ocorriam por "atos inseguros - e aqui entra a questão da automatização". A revista, bancada por fabricantes de equipamentos, dava como solução para as altas taxas de acidentes o uso de mais máquinas. Em outra edição, matéria da revista repetiu a mesma alegação: "No Brasil, praticamente [sic] noventa e oito por cento em cada cem acidentes são provocados por atos inseguros, por condições inseguras ou pelos dois fatores em conjunto" (O EMPREITEIRO, 1981, p. 3).

O que se nota na ditadura é que, além de culpabilizar o operário pelo acidente do qual ele foi vítima, a displicência com os equipamentos de segurança no canteiro era um bom negócio para os empreiteiros. Diante da situação política,sindical e da limitação dos organismos fiscalizadores, era lucrativo para as empresas manter obras sem aparatos de segurança adequados para o operário. A Lei Orgânica de Previdência Social (Lops), de 1966, que criou o INPS, implantou um seguro para os trabalhadores que sofriam acidentes, sendo que o custo de manutenção do operário, após 15 dias de afastamento, não onerava o patrão (apud ANDRADE, 1999). Quem acabava arcando com o afastamento dos operários de licença eram os próprios trabalhadores, com suas poupanças compulsórias descontadas na folha de pagamento. Com isso e com a precária fiscalização ao cumprimento das normas, era lucrativo para o empresário não prover segurança adequada ao trabalhador. A respeito disso, a revista O Empreiteiro $(1976$, p. 3) afirmou: "É fato notório que há empresas construtoras que preferem pagar multas por falta de materiais de segurança na obra, do que instalá-los no canteiro". O que o periódico não informava era que as multas eram raras e seus valores, módicos. Em outra edição, matéria sobre o alto número de acidentes afirmava que, dentre as obras tocadas por empreiteiras, "[...] a segurança em geral é limitada e entravada por ser considerada anti-econômica." (O EMPREITEIRO, 1974). Segundo um empresário entrevistado por Mirian Rocca (1991, p. 66), havia normas do Ministério do Trabalho para garantir a segurança do operário, mas, para ele, "seguir todas as regras complica muito." Nesse mesmo sentido, empresários explicavam a não adoção de equipamentos de segurança pela redução na rentabilidade: "Existe um custo para que efetivamente se implante a segurança, para que funcione. Do ponto de vista da produtividade, não parece alterar. Portanto, absorver esse custo não é válido." (ROCCA, 1991, p. 67). E o trabalhador era culpabilizado pelo não uso dos equipamentos: "O peão dá mais valor quando paga a bota ou o capacete. Caso contrário, ele não cuida do material, perde, vende, quebra, etc." (ROCCA, 1991, p. 68). Entrevistando operários, Maria Klausmeyer (1988) verificou em uma obra que estucadores trabalhavam sem cinto, que a maioria das obras não tinha CIPA, que acidentes não levavam a afastamento ou não eram notificados e que não havia cursos de segurança. 


\section{AeVistg all paUtg}

\} OS EMPREITEIROS DE OBRAS PÚBLICAS - CAMPOS, P. H.P. \}

Com o alto índice de acidentes na construção, o governo, ao invés de reforçar a fiscalização e multar empresas fora das normas, determinou, em 1976, que o INPS destinasse $2 \%$ da receita do seguro por acidentes de trabalho para financiar sem juros a compra de equipamentos de segurança pelas empresas (O EMPREITEIRO, 1976). Assim, o aparelho de Estado entrava com crédito subsidiado para proporcionar equipamentos que deveriam constar como obrigatórios nos canteiros. No final das contas, as políticas do Estado ditatorial brasileiro, além de potencializar os lucros pela política salarial e demais medidas voltadas para a classe trabalhadora, impulsionaram também os acidentes de trabalho, ao transformá-lo em um bom negócio do ponto de vista empresarial, sendo que as próprias tentativas de atenuar os índices de acidentes ocorriam em detrimento dos recursos públicos.

Diante do caráter público e flagrante dos acidentes de trabalho e sua elevação ao longo do regime, houve movimento para dar resposta à tendência e algumas medidas foram tomadas para atenuar as estatísticas. Apesar dessa movimentação no aparelho de Estado, nenhuma decisão incorreu em radical alteração das posturas dos empresários para proporcionar um adequado sistema de segurança ao trabalhador ou em onerar substancialmente os empregadores pelos acidentes ocorridos com os operários. Uma primeira decisão foi a convocação, em 1976, pelo Ministério do Trabalho, do I Congresso Nacional de Prevenção de Acidentes na Construção (Conpac) (O EMPREITEIRO, 1976). Após essa iniciativa, medidas foram tomadas para tentar reduzir os acidentes no setor. Em dezembro de 1977, o decreto-lei $n^{\circ} 6469$ estabelecia a responsabilidade técnica da empresa de engenharia, que ficava sujeita a ser chamada aos tribunais para assumir responsabilidades legais e indenizar as vítimas dos acidentes (apud O EMPREITEIRO, 1978). Apesar do caráter aparentemente duro da deliberação, não houve substantiva modificação nas condições de segurança ou grave punição das empresas.

A partir das mobilizações dos operários, a velocidade do processo de implantação de aparatos de segurança no canteiro se modificou. Com as agitações no ABC paulista, em 1978, editorial da revista O Empreiteiro (1978) sentenciou: "Talvez num prazo menor do que muitos imaginam, os empresários terão que sacrificar uma parte dos seus lucros na melhoria das condições de trabalho dos seus operários.". A revista passou a evocar a melhora das condições de vida, segurança e trabalho dos operários no canteiro, alertando para os seus benefícios em produtividade. A movimentação dos operários, e o fato de o tema da segurança no trabalho constar nas pautas de reivindicações das mobilizações e greves na passagem das duas décadas, levou a mais medidas do governo federal. Em 1978, portaria do Ministério do Trabalho determinou a criação de comissões internas para prevenção de acidentes em todos locais com mais de 50 empregados. Além disso, o decreto 68.255, de fevereiro de 1981, criou em caráter emergencial 
a Campanha Nacional de Prevenção de Acidentes de Trabalho (apud O EMPREITEIRO, 1981).

As mobilizações dos trabalhadores e as medidas estatais tiveram respostas diferenciadas nas empresas. Enquanto a maioria tentava manter as mesmas relações com os trabalhadores existentes nos anos mais duros do regime, outras encamparam o tema da segurança do trabalhador e a minimização dos acidentes. A paulista Adolpho Lindenberg lançou a revista Cal-CIPA, com normas de higiene e segurança para os canteiros (O EMPREITEIRO, 1978). Em 1979, construtoras cariocas, como a Carvalho Hosken, Veplan, João Fortes e a Servenco, promoveram a Semana de Prevenção de Acidentes, com cursos para os operários e instrução sobre equipamentos de segurança. E a também carioca Wrobel orientou os operários sobre segurança e parece ter sido pioneira no cumprimento estrito das normas legais e de países mais avançados, propondo ainda a "democracia interna na construtora" (KLAUSMEYER, 1988, p. 55-140). ${ }^{10}$

Apesar dessas iniciativas localizadas, tomadas em função da pressão operária e para dar aparência de "modernidade" junto ao governo e à população, as condições de trabalho e segurança dos operários da construção se mantiveram em um nível precário durante a transição política dos anos 1980, quando as mobilizações operárias foram cada vez mais intensas, chegando às grandes revoltas dos últimos anos do regime.

\section{Greves, revoltas e quebra-quebras nos canteiros de obras}

Já nos primeiros momentos da distensão, começaram a ocorrer as mobilizações de trabalhadores. Após longo período em seguida às greves de 1968, as paralisações experimentaram tendência ascendente no governo Geisel, agravadas pela inflação e atenuação da expansão econômica ${ }^{11}$. Na construção, os dissídios viraram recorrentes e o Sinicon passou a ter como uma de suas principais funções a intermediação de conflitos entre empresas e empregados (SINICON,1985). Em 1979, veio à tona a questão e, com a redução dos ganhos no setor, os empresários tentavam manter sua taxa de lucro à custa dos empregados:

Com a aproximação de um dissídio coletivo, as negociações entre empregados e patrões são encaminhadas através de um processo normalmente cansativo e prolongado. Na construção civil, nos últimos anos, entretanto, as negociações sempre chegaram a um bom termo, mantendo sobretudo um entendimento sem maiores problemas. Este ano, porém, os empresários estão seriamente preocupados com a si-

\footnotetext{
${ }^{10} \mathrm{O}$ caso foi analisado por Nilton Vargas em A prática da fraqueza e da 'discordância': a participação dos trabalhadores na gestão de uma construtora. Rio de Janeiro: Finep/Coppe/Wrobel, 1984.

${ }^{11}$ Sobre os empresários e as greves 1977-8, ver CRUZ, Sebastião Velasco e. O Presente como História: economia e política no Brasil pós-64. ColeçãoTrajetória, n. 3. Campinas: EdUnicamp, 1997.p. 313-54.
} 


\section{ReVistg all paUtg}

\} OS EMPREITEIROS DE OBRAS PÚBLICAS - CAMPOS, P. H.P. \}

tuação do mercado, estagnado desde o ano passado. (O EMPREITEIRO, 1979, p. 3).

A mensagem do editor da revista $O$ Empreiteiro (1979) indica uma marca que se repetiria desse ano em diante, a de difíceis negociações entre empresários e operários em torno do reajuste salarial e outras exigências trabalhistas.

Dado o caráter do regime e as decisões judiciais pró-empresários, a forma como os trabalhadores reivindicavam seus direitos não se dava apenas com negociações classistas, mas muitas vezes com revoltas, rebeliões e quebra-quebras, os quais Nair Sousa (1994, p. 204-44) intitulou de "cidadania do protesto". Desde fins dos anos 1970, ocorreram sublevações de operários nos canteiros do metrô do Rio ${ }^{12}$ e eram comuns motins similares de usuários de serviços públicos, como os trens suburbanos, em protesto contra tarifas elevadas (MENDONÇA; FONTES, 1988; SINICON, 1985). No caso dos quebra-quebras de trabalhadores, eles giravam em torno de exigências e em função de acidentes e mortes de operários. Houve um caso ocorrido no Rio em que o delegado do trabalho visitou a obra paralisada, que exibia o cartaz "Revoltados", posto pelos operários, e verificou péssimas condições do alojamento, horas extras não recebidas e um operário morto (KLAUSMEYER, 1988).

Algumas características comuns eram visíveis nos levantes de trabalhadores na indústria da construção. Além dos acidentes, outra motivação imediata era a das condições de alimentação. Ocorriam mobilizações e expressões de violência dos operários em função de cardápios limitados ou de condições de higiene inadequadas no trato dos alimentos, sendo a cantina um local explosivo, indicada por Nair Sousa (1994) como o "calcanhar de Aquiles" do canteiro ${ }^{13}$. O Jornal do Brasil de 8 de novembro de 1978 relata um caso ilustrativo:

Operários depredaram às $18: 30$ hrs. a cantina do canteiro de obras da empresa X. Alegaram que a comida servida estava podre e azeda, provocando diariamente dores de barriga, desinteria, levando alguns deles ao hospital. Depois de quebrarem toda cantina, os operários lançaram na rua panelas, restos de comida, mantimentos, botijões e até um fogão a gás. (apud KLAUSMEYER, 1988, p. 55-140)

O periódico silenciava na identificação da empresa, mas o caso parece se referir a uma obra imobiliária urbana no Rio. Apesar de levantes como esse nos canteiros em cidades, motins de trabalhadores de grandes obras públicas eram ainda mais violentos.

\footnotetext{
${ }^{12}$ Analisado por VALLADARES, L. P. “O caso dos operários do Metrô do Rio de Janeiro. In: Cidade, Povo e Poder. Rio de Janeiro: Paz e Terra, 1982.

${ }^{13} \mathrm{O}$ que ela verificou também nas obras de Brasília em Souza (1978).
} 
Um caso ocorreu em Belo Horizonte em 1978, quando operários da construção civil da capital mineira se uniram para reivindicar $100 \%$ de aumento dos salários, paralisando os trabalhos. Diante da intransigência dos empregadores em aceitar a reivindicação e com a repressão policial às manifestações, houve intenso quebra-quebra na cidade, com automóveis virados e incendiados, lojas com vitrines destruídas e o tratorista Orocílio Martins Gonçalves, de 24 anos, morto pela polícia em meio aos protestos. Segundo a revista O Empreiteiro (1981), o ocorrido expunha cenas "que estamos acostumados a ver em Belfast e Beirute". Diante da ameaça de intervenção federal no estado e ação das forças armadas, o governador Francelino Pereira cedeu estádio de futebol para as assembleias dos grevistas e distribuiu alimentos entre eles. Em outra mobilização na capital mineira, o sindicato, próximo aos empregadores, foi destituído: "Ao mesmo tempo, uma verdadeira central sindical virtualmente destituiu Pizarro, deixando o comando da greve para sindicalistas mais experientes. Até Lula participou." (O EMPREITEIRO, 1980, p. 3)

Apesar da revolta em Belo Horizonte, o maior levante em canteiros na ditadura se deu na obra da hidrelétrica de Tucuruí. De acordo com a memória de Wilson Quintella (2008, p. 15-24), diretor da empresa responsável pela obra, a Camargo Corrêa, o tratamento dado aos operários era exemplar: "Na organização dos acampamentos de trabalho, proporcionávamos vida de Primeiro Mundo ao nosso pessoal." Esse cuidado, segundo seu relato, começava com pagamentos rigorosamente em dia:

Tinham preferência as grandes obras, com milhares de funcionários no canteiro, alguns recém-contratados. Todos precisavam receber o salário na data marcada. Caso contrário, o encarregado da obra não teria como controlar o pessoal. Essa foi uma das razões pelas quais nunca enfrentamos tumultos em nossos canteiros (QUINTELLA, 2008, p. 199224 - grifos nossos).

Apesar da imagem idílica apresentada pelo dirigente da construtora, a informação de não ter havido problemas nos canteiros da empresa não corresponde à realidade vivida na ditadura.

A edição de maio de 1980 da revista O Empreiteiro trazia na capa uma imagem aérea do canteiro destruído de Tucuruí com o título "A revolta chega aos canteiros". A reportagem trazia críticas aos empreiteiros, em particular à Camargo Corrêa e já no editorial, Joseph Young defendia que "é necessária uma nova mentalidade empresarial que olhe para os interesses sociais com mais carinho". O título da reportagem trazia nova acusação contra as condições de vida e trabalho impostas pela empreiteira: "Motim no canteiro - os operários se revoltam. Mas com tantas pressões assim, quem é que não se revolta?" (O EMPREITEIRO, 1980).

A sublevação ocorria na segunda maior obra do país, a hidrelétrica de Tucuruí, a cargo exclusivo da Camargo Corrêa. A obra reunia 25 mil 


\title{
AeVistg all paUtg
}

\} OS EMPREITEIROS DE OBRAS PÚBLICAS - CAMPOS, P. H.P. \}

operários e tinha como agravante o isolamento do canteiro na floresta amazônica, nas bordas do rio Tocantins. Segundo a revista O Empreiteiro (1980, p. 10), a construtora instalou no ambiente "alguns requintes inéditos", como uma repetidora de TV - praxe nas obras de barragem e uma forma de ocupar os trabalhadores em seus horários de descanso - que transmitia os programas da Rede Globo desde 1978.

\begin{abstract}
Este e outros requintes não parecem ter solucionado o problema comum aos canteiros: a violenta tensão social. Em Tucuruí, ela explodiu na madrugada de sábado de Aleluia. Os peões revoltados quebraram dois refeitórios, saquearam o supermercado que serve à vila dos operários e atearam fogo ao centro de vigilância. Rapidamente, as forças da polícia militar paraense intervieram com violência, que resultou em cinco peões feridos, dois com gravidade e um baleado no estômago - José Carlos Ferreira, de 20 anos, que foi removido para o Hospital Santa Izabel, em São Paulo, depois de atendido no hospital do canteiro. A revolta começou com uma brincadeira dos peões: a malhação de um judas que representava um dos vigilantes da Camargo Corrêa. Vi-gilantes fortemente armados confiscaram o judas e prenderam os peões que comandavam a brincadeira.
\end{abstract}

Como informado na reportagem, a revolta teve início na Semana Santa, quando operários fizeram um boneco vestido com a roupa da empreiteira e o malharam como um judas. A gozação teve repressão do sistema de vigilância e assim foi deflagrada a revolta.

Operários informaram à revista Isto é que o levante se deveu à violência como foram feitas as prisões, com chutes e ameaça de armas. $\mathrm{O}$ ápice do levante se deu quando os presos eram nove e mesmo após sua libertação, o motim continuou, com demanda de aumento de $100 \%$ dos salários e melhorias nos alojamentos, transportes e alimentação. Operários reclamavam que a última refeição consistia em arroz, feijão e ovo e a empresa afirmava que houve ali um problema isolado de logística. Com o aumento da tensão no canteiro, a polícia do Pará foi ao local e reprimiu os operários. Segundo a revista O Empreiteiro (1980, p.12), "foi necessário o uso de bombas de gás e alguns tiros para o alto."

A revista O Empreiteiro (1980) fez uma reportagem especial sobre o tema, entrevistando outros empresários e o sociólogo César Falcão. Dentre divagações sobre o caráter isolado e confinado do canteiro, Falcão ressaltou: "A revolta de Tucuruí, por exemplo, não à toa começou no alojamento I3 , que tem os operários sem qualificação e que estão em período de experiência, o que é o maior foco dos motins." ( O EMPREITEIRO, 1980, p. 12).

Outros levantes na construção civil mostram que a estratificação de ganhos e condições dos operários são fatores de reclamação e protestos, fazendo com que os operários com menor salário e qualificação sejam os 
mais enérgicos nessas situações. A revista O Empreiteiro (1980, p. 11) demarcava os prejuízos para a empresa:

A Camargo Corrêa montou alojamentos sofisticados, mas na primeira vez que faltou carne na refeição (por simples problema de transporte, diz a empresa), os peões se revoltaram e proporcionaram alguns prejuízos materiais, de resto insignificantes quanto ao atraso imposto às obras.

A matéria insinua, em certo apoio à empresa, que essa teria sido a primeira falta de carne. Como contraponto, a revista foi entrevistar Luís Coelho, da Serveng-Civilsan, que indicou como a empresa fazia para evitar eventos similares. Afirmou que a sua firma tinha boas relações com os trabalhadores, devido à alimentação e salários, sendo que "a data de pagamento dos salários é coisa sagrada." Indicava ele que a alimentação contava sempre com arroz, feijão e carne, sendo que a última era indispensável e devia ser farta. Afirmava não usar segurança ostensiva, como fazia a Camargo Corrêa, pela má impressão para o operário, que se "sente marginalizado" e porque o "canteiro fica parecendo campo de concentração" (O EMPREITEIRO, 1980).

Historicamente, a Camargo Corrêa era conhecida por sua truculência e tratamento de segunda ordem dado aos operários. Sebastião Camargo, o empresário que doou dinheiro para o aparato de repressão e tortura da Operação Bandeirantes, era o mesmo que acumulava as maiores insatisfações e sublevações nos canteiros de obras. Mais de 20 anos após o fim da ditadura, a mesma empreiteira protagonizou outra revolta de operários nos canteiros da obra da usina de Jirau, no rio Madeira, também em condições adversas de isolamento e violência arbitrária por parte dos fiscais da empresa (O GLOBO, 2011).

Independentemente do comportamento de uma ou outra empresa, uma face da violência e truculência do regime se expressava sob a forma como o controle era exercido nos canteiros em seus projetos de engenharia. O tratamento inadequado, as péssimas condições do alojamento, de alimentação, a falta de segurança, que levava às elevadas taxas de acidentes, além das ilegalidades cometidas, como sub-contabilização das horas extras e não respeito às leis de trabalho, eram medidas praticadas pelas empresas que tinham pleno respaldo do aparelho de Estado e das políticas públicas. Se o governo beneficiava os empresários com subvenções, reserva de mercado, incentivos financeiros, isenções e demanda de obra, outra face do favorecimento das construtoras brasileiras se dava através das políticas para os trabalhadores, que incluíam arrocho salarial, desrespeito às leis trabalhistas, coerção sobre as suas formas de organização, enfraquecimento dos mecanismos fiscalizadores de segurança, dentre outras medidas e orientações das políticas estatais. As medidas praticadas pelo regime, que incorriam em uma piora das condições de vida dos operários 


\section{pevistg ell pallg}

\} OS EMPREITEIROS DE OBRAS PÚBLICAS - CAMPOS, P. H. P. \}

da construção, serviam para potencializar os lucros das empresas do setor. Assim, o caráter classista e empresarial do regime se expressava tanto pelas políticas voltadas para o capital, quanto pelas políticas endereçadas aos tra-balhadores. 


\section{Revista pll paltg}

\} OS EMPREITEIROS DE OBRAS PÚBLICAS - CAMPOS, P. H.P.\}

\section{Referências}

ANDRADE, E.G. $O$ (des)equilíbrio da previdência social brasileira, 19451997: componentes econômico, demográfico e institucional. Tese de doutoramento em Demografia. Belo Horizonte: CEDEPLAR/FACE/UFMG, 1999.

ALMEIDA, C. Quebra-quebra na usina de Jirau. O Globo. Rio de Janeiro, 17 mar. 2011.

BRASIL. COMISSÃO NACIONAL DA VERDADE. Seminário - Como as empresas apoiaram e beneficiaram a ditadura militar. São Paulo, Comissão Nacional da Verdade, 15 mar. 2014.

CHAVES, M. Indústria da construção no Brasil: desenvolvimento, estrutura e dinâmica. Dissertação de mestrado em Economia Industrial. Rio de Janeiro: UFRJ, 1985.

COUTINHO, R. L. Operário de construção civil: urbanização, migração e classe operária no Brasil. Rio de Janeiro: Achiamé, 1980.

FUNDAÇÃO JOÃO PINHEIRO. Diagnóstico nacional da indústria da construção. Belo Horizonte: Fundação João Pinheiro, 1984. Sumário executivo. GORENDER, J. Combate nas trevas. São Paulo: Ática, 1987.

IANNI, O. A ditadura do grande capital. Rio de Janeiro: Civilização Brasileira, 1981.

KLAUSMEYER, M. L. C. O peão e o acidente de trabalho na construção civil no Rio de Janeiro: elementos para uma avaliação do papel da educação nas classes trabalhadoras. Dissertação de mestrado em Educação. Rio de Janeiro: FGV, 1988.

LOBO, E. M. L.; OLIVEIRA, A. O Estado Novo e o sindicalismo corporativista, 1937-1945. In: LOBO, E. M. L. (Org.). Rio de Janeiro operário: natureza do Estado, a conjuntura econômica, condições de vida e consciência de classe, 1930-1970. Rio de Janeiro: Access, 1992.

MARINI, R. M. Dialética da dependência. Petrópolis/Buenos Aires: Vozes/ Clacso, 2000.

MARX, K. O capital. 2 ${ }^{a}$ ed. Coleção Os Economistas. São Paulo: Nova Cultural, 1985 [1867].

MENDONÇA, S. R.; FONTES, V. História do Brasil recente: 1964-1992. 4⿳亠丷a ed. atualiz. São Paulo: Ática, 1996 [1988].

MORAES, V. Crônica Toadinha de Ano Novo. In: Para uma menina com uma flor: crônicas. Rio de Janeiro: Editora do autor, 1966.

OLIVEIRA, F. A crítica da razão dualista. São Paulo: Boitempo, 2003 [1972]. 


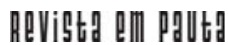

\} OS EMPREITEIROS DE OBRAS PÚBLICAS - CAMPOS, P. H. P.\}

QUINTELLA, W. Memórias do Brasil grande: a história das maiores obras do país dos homens que as fizeram. São Paulo: Saraiva/Vigília, 2008.

REVISTA O EMPREITEIRO. São Paulo, n· 25, ed. fev. 1970.

. São Paulo, n. 82, ed. nov. 1974.

. São Paulo, n. 85, ed. fev. 1975.

. São Paulo, n. 101, ed. jun. 1976.

. São Paulo, n. 104, ed. set. 1976.

. São Paulo, n. 122, ed. mar. 1978.

. São Paulo, n. 125, ed. jun. 1978.

. São Paulo, n. 127, ed. ago. 1978.

. São Paulo, n. 129, ed. out. 1978.

. São Paulo, n. 134, ed. mar. 1979.

. São Paulo, n. 148, ed. mai. 1980.

. São Paulo, n. 152, ed. set. 1980.

. São Paulo, n. 161, ed. mai. 1981.

. São Paulo, n. 164, ed. ago. 1981.

ROCCA, M. C. Uma das faces do capitalismo selvagem no Brasil: a (in)segurança do trabalho na construção civil. Dissertação de mestrado em Serviço Social. São Paulo: PUC-SP, 1991.

SINGER, P. I. A crise do "milagre": interpretação crítica da economia brasileira. 4⿳亠丷a ed. Rio de Janeiro: Paz e Terra, 1978 [1977].

SINICON. Informe. n. 5, ano I, 1984.

. n. 27, ano I, 1984.

.n. 14, ano II, 1985.

.n. 15, ano II, 1985.

. n. 16, ano II, 1985.

SOUSA, N. H. B. Trabalhadores pobres e cidadania: a experiência da exclusão e da rebeldia na construção civil. Tese de doutorado em Sociologia. São Paulo: USP, 1994.

. Operários e política: estudo sobre os trabalhadores da construção civil em Brasília. Dissertação de mestrado em Ciências Sociais. Brasília: UnB, 1978. p. I-XII.

Recebido em 27 de julho de 2014.

Aprovado para publicação em 30 de julho de 2014. 


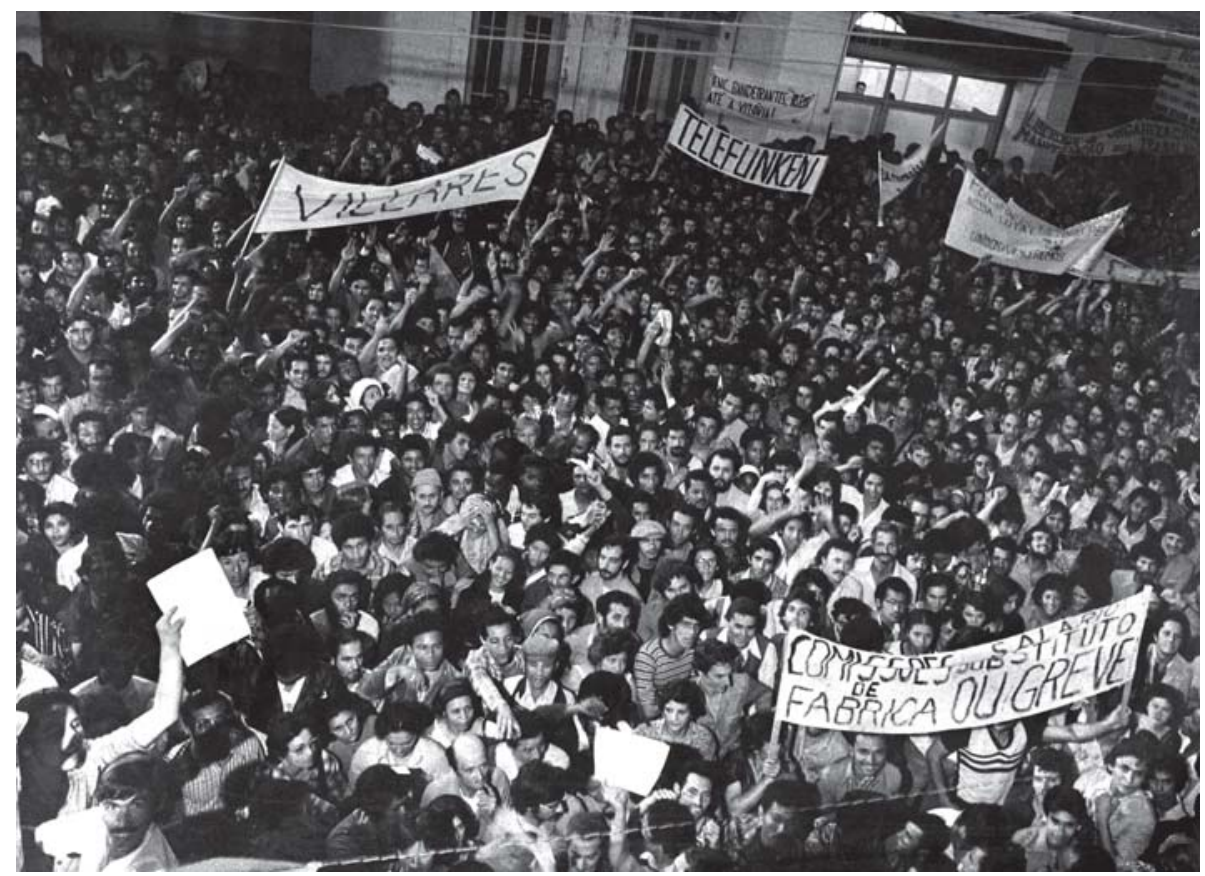

Metalúrgicos na "Assembléia dos 30 mil". Sindicato dos Metalúrgicos de São Paulo. 1979. Oposição Sindical Metalúrgica de São Paulo. IIEEP 